\title{
Suppressive Effect of Fermented Angelica tenuissima Root Extract against Photoaging: Possible Involvement of Hemeoxygenase-1
}

\author{
Yun-A Park ${ }^{1 \dagger}$, Sung Ryul Lee ${ }^{2 \dagger}$, Jin Woo Lee ${ }^{1}$, Hyun Jung Koo ${ }^{3}$, Seon-A Jang ${ }^{4}$, Seung-Won Yun ${ }^{5}$, Hyun Ju Kim ${ }^{5}$, \\ Jeong Suk $\mathrm{Woo}^{5}$, Myung Rye Park ${ }^{6}$, Se Chan Kang ${ }^{4 *}$, Youn Kyu Kim ${ }^{6 *}$, and Eun-Hwa Sohn ${ }^{1 *}$ \\ ${ }^{1}$ Department of Herbal Medicine Resource, Kangwon National University, Samcheok 25949, Republic of Korea \\ ${ }^{2}$ Department of Convergence Biomedical Science, Cardiovascular and Metabolic Disease Center, College of Medicine, Inje University, Busan \\ 47392, Republic of Korea \\ ${ }^{3}$ Department of Medicinal and Industrial Crops, Korea National College of Agriculture and Fisheries, Jeonju 54874, Republic of Korea \\ ${ }^{4}$ Department of Oriental Medicine Biotechnology, College of Life Sciences, Kyung Hee University, Yongin 17104, Republic of Korea \\ ${ }^{5}$ Chungbuk Technopark, Cheongju 28115, Republic of Korea \\ ${ }^{6}$ Korea Research Institute Bio Science Co., Ltd., Yeoju 12668, Republic of Korea
}

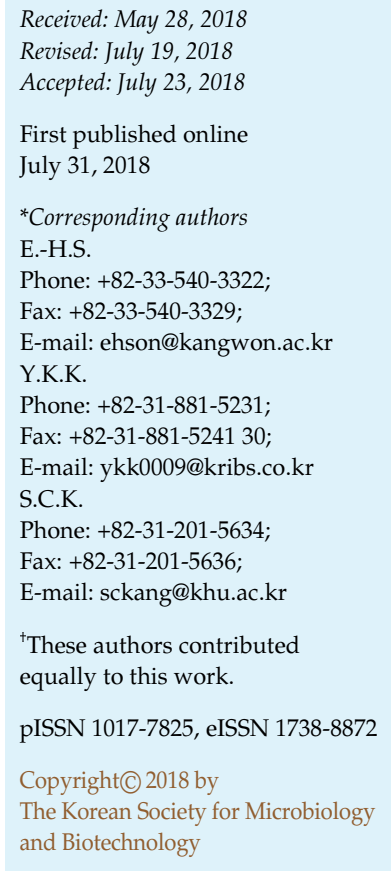

Angelica tenuissima root has historically been used as a traditional medicine in Korea. Previous studies have identified the anti-melanogenic effects of the extract of A. tenuissima root fermented by Aspergillus oryzae (FAT). This study investigated the protective effects of FAT against ultraviolet light B exposure (UVB; $30 \mathrm{~mJ} / \mathrm{cm}^{2}$ ) in HaCaT (human keratinocyte) or Hs68 (human foreskin fibroblast) skin cells. FAT treatment was able to stimulate wound healing rate at the basal condition. FAT also favored the maintenance and/or improvement of extracellular matrix impairment caused by UVB irradiation through: 1) upregulation of procollagen Type-1 synthesis and secretion; 2) suppression of MMP-1 and elastase expression. FAT was able to play a role in the attenuation of inflammatory responses caused by UVB irradiation via upregulation of photo-protective hemeoxygease- 1 and suppression of proinflammatory cyclooxygenase-2 expression. After further verification of the anti-photoaging potential of FAT, it could be utilized as an effective ingredient in anti-aging and anti-wrinkle cosmetics.

Keywords: Angelica tenuissima, photoaging, fermentation, ultraviolet light B, hemeoxygenase-1, extracellular matrix

\section{Introduction}

The skin functions as the body's primary line of defense against external environments and maintains body moisture. Besides the biological functions of the skin, clear skin is a very important part of a satisfactory appearance, as an indicator of youth and beauty, especially for Asian women [1]. Photoaging of the skin is associated with innate biologic aging processes and their interactions with environmental influences, such as sun-light and pollutants [2]. Chronically sun-exposed skin is prone to increased oxidative damage mediated by ultraviolet (UV) irradiation and thus is short-lived and less sensitive to population doubling as well as response to mitogenic stimuli [2]. Photoaging in skin causes wrinkles and hyperpigmentation, which are unfavorable in the maintenance of healthy skin and cosmetic appearance. For these reasons, numerous approaches have been undertaken in the cosmetic industry to maintain healthy skin or prevent aging [2].

Natural products are a rich reservoir for discovering new bioactive compounds because of their diversity and complexity structures. The use of various natural products 
to protect against skin aging has recently been proposed; these include ginseng, aloe vera, berries, and porcine placenta [3]. Angelica tenuissima Nakai (Ligusticum tenuissimum Kitagawa) belongs to the family Umbelliferae and grows in certain areas of China and rocky slopes on the Korean peninsula [4]. The root of A. tenuissima Nakai (ATE), especially when collected during the fall season, has been used in traditional medicine to treat various types of pain and in remedies for women with gynecological diseases and anemia in Asia [5, 6]. Recently, interferon-mediated anti-viral, anti-osteoporosis, and anti-inflammatory activities of ATE have been identified [7-9]. Besides health concerns, the cosmetic uses of natural plant extracts have been extensively explored, because good and healthy appearance is another concern of an individual's quality of life. It has been widely recognized that fermentation of natural plants may reduce allergens, as well as to enrich the intestinal bioavailability of bioactive agents $[10,11]$. In our previous study, we reported that fermented A. tenuissima roots (FAT) possess higher content of decursin and Z-ligustilide compared to the non-fermented counterpart, A. tenuissima root (AT), showing enhanced anti-melanogenic capacity by suppressing melanin production and tyrosinase activity [12]. However, the cosmetic uses of FAT root to counter photoaging have not been investigated.

In this study, we evaluated the anti-photoaging potential of FAT in in vitro keratinocyte HaCaT cells and/or fibroblast Hs68 cells with or without UVB irradiation $\left(30 \mathrm{~mJ} / \mathrm{cm}^{2}\right)$, which is a major contributor to skin photoaging $[2,13]$. First, the wound healing effect of FAT was determined by a cell migration assay. To confirm the maintenance of extracellular matrix (ECM) components, specifically the collagen and elastin content in the dermal layer, we next examined the stimulatory effect of FAT on the production and secretion of procollagen Type -I (PIP) in Hs68 cells by immunoblot and ELISA analysis. In addition, the expression level of matrix metalloproteinase-1 (MMP-1) and elastase, which are collagen- and elastindegrading enzymes, were determined with or without UVB irradiation by quantitative PCR (qPCR). Finally, changes in the protein expression level of photoprotective hemeoxygenase-1 (HO-1) and proinflammatory cyclooxygenase2 (COX-2) were determined in the presence of FAT.

\section{Materials and Methods}

\section{Chemical and Reagents}

Dulbecco's modified eagle medium (DMEM) and fetal bovine serum (FBS) were obtained from Gibco (USA). 3-(4,5-Dimethylthiazol- 2-yl)-2,5-diphenyltetrazolium bromide (MTT), zinc protoporphyrin IX (ZnPP), dimethylsulfoxide (DMSO), and transforming growth factor- $\beta 1$ (TGF- $\beta 1$ ) were purchased from Sigma-Aldrich Korea (Korea). The primary antibodies against procollagen type-1, COX2 , and $\beta$-actin were obtained from Santa Cruz Biotechnology (USA) and the anti-HO-1 antibody was purchased from Cell Signaling Technology (USA). The Procollagen type 1 C-Peptide (PIP) EIA kit was purchased from Takara (Japan). Aspergillus oryzae was obtained from the Korea Research Institute Bio Science Co., Ltd (Korea). Collection for Type Cultures. Unless indicated otherwise, all other chemicals were also obtained from SigmaAldrich.

\section{Preparation of Angelica tenuissima Root Extract}

A. tenuissima Nakai roots were purchased from the Jaechun Oriental Medicine Market and identified by Dr. S.C. Kang of Kyung Hee University. Voucher specimens were deposited at the herbarium of the School of Medicine at Kyung Hee University. The dried A. tenuissima roots were chopped into small pieces and extracted in $70 \%$ ethanol at $80^{\circ} \mathrm{C}$ for $4 \mathrm{~h}$. The extract was subsequently filtered to remove any particulates and was concentrated under vacuum at $50^{\circ} \mathrm{C}$ to 53 Brix. The extract was lyophilized to obtain a powder and stored at $-20^{\circ} \mathrm{C}$ until further analysis. To prepare the fermented product of A. tenuissima, fermentation was carried out in two steps: seed and main cultures. The seed cultures were prepared by inoculating $100 \mathrm{ml}$ of LB (Luria-Bertani) medium with A. oryzae in a 250-ml Erlenmeyer flask and incubating at $37^{\circ} \mathrm{C}$ for $48 \mathrm{~h}$. The main culture was prepared by adding $20 \%$ (weight/volume) of the A. tenuissima root extract $(100 \mathrm{~g} / \mathrm{l})$ to $2 \mathrm{~L}$ of $\mathrm{LB}$ medium with $100 \mathrm{ml}$ seed culture. Each batch was cultured at $37^{\circ} \mathrm{C}$ for $48 \mathrm{~h}$ with shaking at $50 \mathrm{rpm}$. The broth was extracted with ethanol (1:1 volume ratio) at $80^{\circ} \mathrm{C}$ for $4 \mathrm{~h}$, centrifuged at $2,000 \times g$ for $20 \mathrm{~min}$ at $4^{\circ} \mathrm{C}$, and filtered. The supernatant was concentrated and lyophilized to yield a dry extract of fermented A. tenuissima root (FAT).

\section{Cell Culture}

Hs68 (human foreskin fibroblast cell line) and HaCaT (immortalized human keratinocyte cell line) were obtained from the American Type Culture Collection (ATCC, USA). The cells were cultured in DMEM supplemented with $4 \mathrm{mM}$ L-glutamine, $100 \mathrm{IU} / \mathrm{ml}$ penicillin, $100 \mu \mathrm{g} / \mathrm{ml}$ streptomycin, and $10 \%$ heatinactivated FBS. The cells were grown at $37^{\circ} \mathrm{C}$ in fully humidified air with $5 \% \mathrm{CO}_{2}$.

\section{Cell Viability}

Cell cytotoxicity was measured by quantitative colorimetric assay with MTT, which measures the mitochondrial activity of living cells. Hs68 and HaCaT cells in the exponential growth phase were seeded at $1 \times 10^{4}$ cells/well in 96-well tissue culture plates and treated with different doses of FAT $(125-1,000 \mu \mathrm{g} / \mathrm{ml})$ for 24 and $48 \mathrm{~h}$. After incubation with MTT $(150 \mu \mathrm{g} / \mathrm{ml})$ for $4 \mathrm{~h}$, the formazan crystals were dissolved in DMSO, and then the 
optical density at $540 \mathrm{~nm}$ was measured using a Multi-detector microplate reader VICTOR X3 (PerkinElmer, USA). Cytotoxicity was expressed as a percentage of untreated control cells.

\section{Wound Healing Assay}

HaCaT cells were grown to confluence, serum-starved, and scratched with a pipette tip to create a wound. After wounding, cells were washed twice with serum-free medium to remove cell debris and treated with different doses of FAT (125-500 $\mu \mathrm{g} / \mathrm{ml})$. Photographs of the same fields were taken with an Olympus C-7070 camera at 0,12 , and $24 \mathrm{~h}$, and the open wound area was calculated using the Image J program. The relative ratio of wound closure was determined by calculating the ratio of the open surface area at $24 \mathrm{~h}$ to that at the initial time of wounding.

\section{UVB Irradiation and Sample Treatments}

Cells were exposed to UVB light using an UVC 500 UltraViolet Crosslinker (Amersham, Bucks, UK). Briefly, cells at approximately $90 \%$ confluence were incubated with serum free DMEM for $4 \mathrm{~h}$. Then, the cells were covered with phosphate-buffered saline (PBS) and were exposed to UVB light with a total dose of $30 \mathrm{~mJ} / \mathrm{cm}^{2}$. After UVB exposure, the cells were washed with PBS and further cultured in the presence or absence of FAT for the indicated times. The control group was handled in the same manner without UVB irradiation.

\section{ELISA Assays of Procollagen Type-I}

Hs68 cells were seeded at $4 \times 10^{5}$ cells/well in 6-well tissue culture plate. The next day, cells were irradiated with UVB $\left(30 \mathrm{~mJ} / \mathrm{cm}^{2}\right)$ and further cultured in the presence or absence of FAT $(125-1,000 \mu \mathrm{g} / \mathrm{ml})$. The level of Procollagen Type-I in culture media was determined using a commercial PIP EIA Kit (TAKARA Biochemical Inc., Japan) according to the manufacturer's instruction. Values were normalized to total protein concentrations determined by the Bradford Protein Assay.

\section{Measurement of Elastase Activity}

Hs68 cells were seeded at $8 \times 10^{5}$ cells/well in $100 \mathrm{~mm}$ tissue culture dishes. After UVB irradiation $\left(30 \mathrm{~mJ} / \mathrm{cm}^{2}\right)$, cells were cultured in the presence or absence of FAT $(125-1,000 \mu \mathrm{g} / \mathrm{ml})$ for $48 \mathrm{~h}$. Then cells were lysed in PRO-PREPTM protein extraction solution (INtRON, Korea) and cell lysates were collected by centrifugation $(15,000 \times g)$ at $4^{\circ} \mathrm{C}$ for $5 \mathrm{~min}$. To measure the elastase activity, each cell lysate $(100 \mu \mathrm{g}$ protein) was allocated into a 96-well plate and then $2 \mu \mathrm{l}$ of STANA (N-succinyl-trialanyl-p-nitroanilide, $50 \mathrm{mM}$ ) was added. After incubation at $37^{\circ} \mathrm{C}$ for $1 \mathrm{~h}$, the amount of released p-nitroaniline was measured at $405 \mathrm{~nm}$ using the Multi-detector microplate reader VICTOR X3. Elastase activities were expressed as units per milligram of protein.

\section{Quantitative RT-PCR (qRT-PCR) Analysis for Elastase-1 and MMP-1}

Total cellular RNA was extracted using RNAiso Plus (Takara
Biochemical Inc., Japan), and reverse-transcribed to synthesize cDNA using a cDNA Synthesis kit (Takara). Subsequently, PCR amplification was performed using SYBR Premix Ex Taq II (Takara). The reverse transcription protocol was as follows: $65^{\circ} \mathrm{C}$ for $5 \mathrm{~min} ; 42^{\circ} \mathrm{C}$ for $60 \mathrm{~min} ; 95^{\circ} \mathrm{C}$ for $5 \mathrm{~min}$. The two-step PCR amplification protocol was as follows: $95^{\circ} \mathrm{C}$ for $30 \mathrm{sec}$, followed by 40 cycles of: $95^{\circ} \mathrm{C}$ for $5 \mathrm{sec} ; 60^{\circ} \mathrm{C}$ to produce a melt curve.

The primer sequences were as follows: MMP-1 forward $5^{\prime}$-AGT GGC CCA GTG GTT GAA AA-3' and reverse 5'-CCA CAT CAG GCA CTC CAC AT-3'; Elastase-1 forward 5'-TTA CCT GCC CTC TGT GGA CT-3' and reverse $5^{\prime}$-GCA TCC AGA GCG AAC TCC AT-3'; GAPDH forward 5'-GTG GCA AAG TGG AGA TTG CC-3' and reverse 5'-GAT GAT GAC CCG TTT GGC TCC-3'.

\section{Immunoblot Analysis}

The protein concentration was measured using a BCA protein assay kit (Bio-Rad Lab, USA). Samples were diluted with $1 \times$ lysis buffer containing $1 \% \beta$-mercaptoethanol. Equal quantities of cellular protein $(50 \mu \mathrm{g})$ were resolved by $10 \%$ sodium dodecyl sulfate-polyacrylamide gel electrophoresis (SDS-PAGE) and transferred to nitrocellulose membranes. After blocking, the membranes were incubated with the targeted antibody and then with a horseradish peroxidase conjugated secondary anti-IgG antibody. Immunoreactive proteins were visualized using the ECL western blot detection system. The protein level was compared to a loading control, such as $\beta$-actin and/or nonphosphorylated protein

\section{Statistical Analysis}

Each experiment was repeated either three or four times. For qualitative data, the results of a representative experiment are shown. For quantitative data, the results are expressed as mean \pm SEM and were analyzed using one-way ANOVA followed by Tukey's method using SigmaPlot software (Systat Software Inc., USA). A statistical probability of $p<0.05$ was considered significant.

\section{Results}

\section{Cytotoxic Effect of FAT on Hs68 and HaCaT Cells}

To determine the cytotoxicity of FAT, an MTT assay was conducted on $\mathrm{Hs} 68$ and $\mathrm{HaCaT}$ cells at 24 and 48 h. FAT $(125-1,000 \mu \mathrm{g} / \mathrm{ml})$ treatment did not show any significant cytotoxic or cell proliferative effect on Hs68 (Fig. 1A) or HaCaT cells (Fig. 1B).

\section{Wound Healing Effect of FAT}

We investigated the wound healing effect of FAT on $\mathrm{HaCaT}$ cells after scratching a confluent cell layer. FAT $(125-500 \mu \mathrm{g} / \mathrm{ml})$ treated groups showed improved gapfilling compared to the untreated control (Fig. 2A). This suggested that the increased rate of gap-filling mediated by FAT treatment was likely to be associated with active cell 

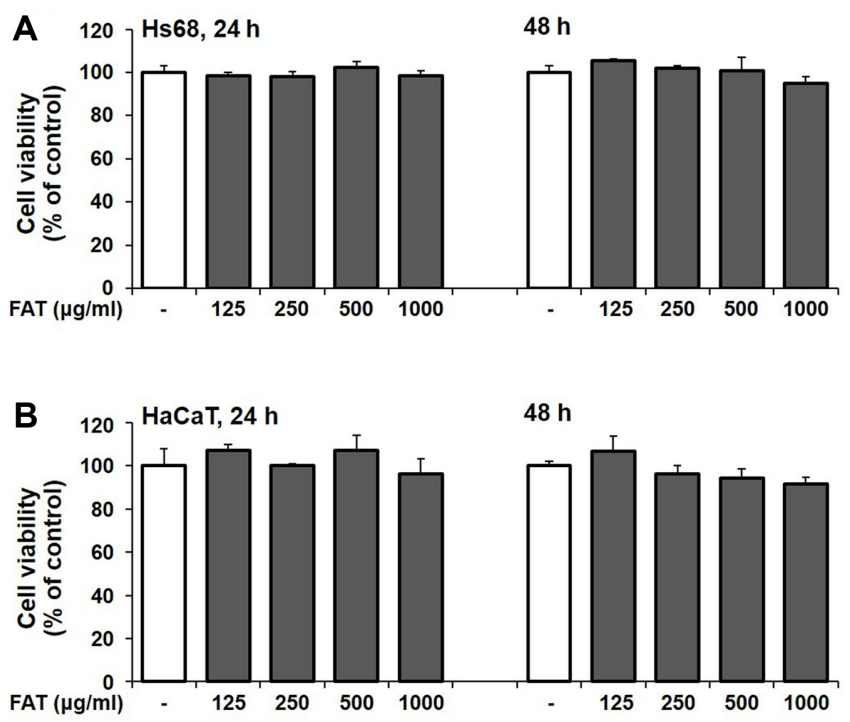

Fig. 1. Cytotoxic effects of FAT in Hs68 and HaCaT cells. Hs68 (A) and HaCaT cells (B) were treated with FAT (125 to $1,000 \mu \mathrm{g} / \mathrm{ml}$ ) for 24 or $48 \mathrm{~h}$. Cell viability was determined by MTT assay. The cell viability of untreated control cells was set at $100 \%$. Data are shown as mean $\pm \operatorname{SEM}(n=9)$. FAT; fermented A. tenuissima root extract.

migration in the scratched area, since FAT treatment was not associated with any significant cell proliferation (Fig. 1B).

UVB is the most dangerous component of sunlight and causes DNA damage and increased oxidative stress, resulting in the appearance of wrinkles, hyperpigmentation, sallowness, and loss of skin tone, which are the main characteristics of photoaged skin [14]. Next, we investigated the effect of FAT on cell migration after UVB $\left(30 \mathrm{~mJ} / \mathrm{cm}^{2}\right)$ exposure. As shown in Fig. 2B, UVB exposure impaired the capacity of wound healing compared to the untreated mock irradiated group. FAT treatment augmented gap filling but did not lead to a significant increase in gap filling after UVB exposure, as shown in Fig. 2B. These results suggest that the gap filling capacity of FAT may be more effective in the absence of cell damage caused by UVB exposure.

\section{Effect of FAT on the mRNA and Protein Expression of Procollagen Type-I and Elastin}

Oxidative stress plays a central role in both agingassociated and UV irradiation-initiated dermal extracellular matrix alterations. UV irradiation induces transient collagen deficit and progressive fragmentation of the dermal collagenous extracellular matrix, which favors wrinkle formation [15]. Thus, we determined the effect of FAT on the synthesis and secretion of procollagen Type I C-peptide
A
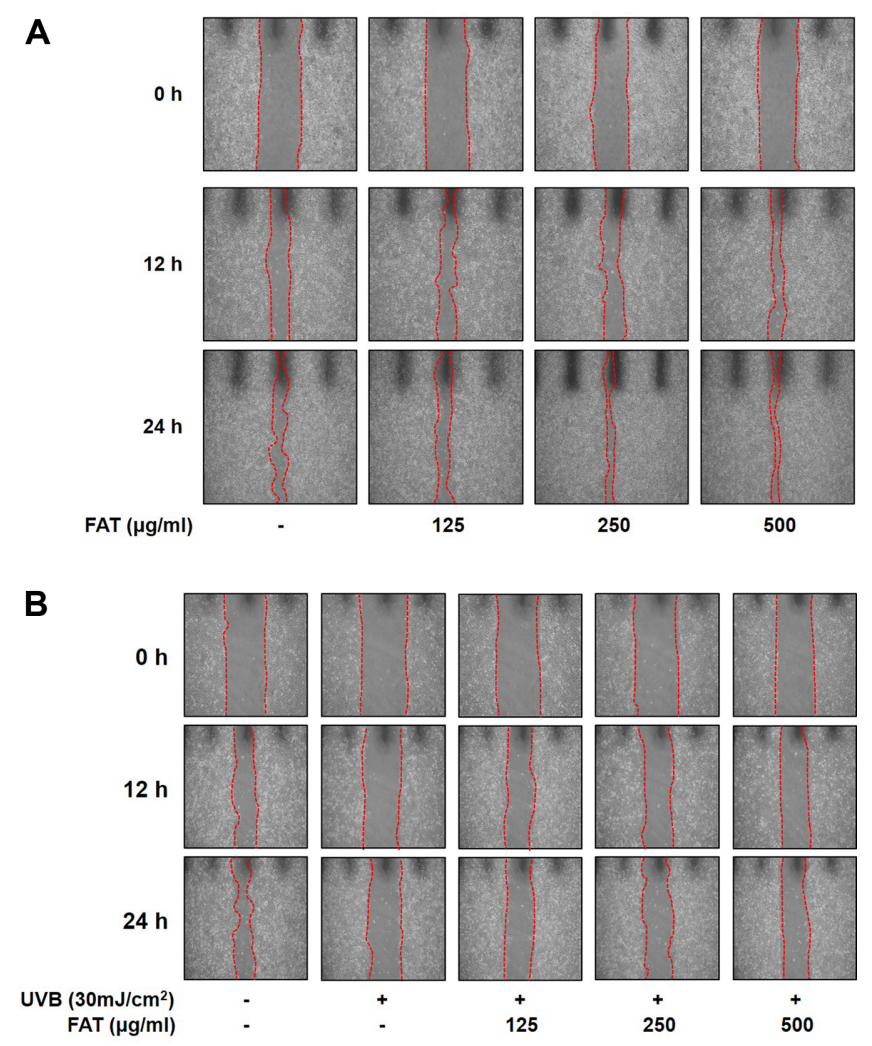

Fig. 2. Effect of FAT on the migration of HaCaT cells.

When HaCaT cells reached $90 \%$ confluence, a wound was made in the presence or absence of FAT by scratching the culture area with a pipette tip. Then, images of cells were captured at 0,12 , and $24 \mathrm{~h}$ (A). Next, cells were exposed to UVB and then a wound was made in the presence or absence of FAT by scratching the culture area. Images of cells were captured at 0,12 , and $24 \mathrm{~h}($ B) .

(PIP) with or without UVB irradiation. Here, TGF- $\beta$ $(10 \mathrm{ng} / \mathrm{ml})$ was used as a control for the production and secretion of procollagen Type-I. In the absence of UVB irradiation, FAT was able to significantly increase ( $>2$-fold) the protein expression level of PIP compared to the control in a dose dependent manner (Fig. 3A). UVB irradiation a reduction PIP expression of over $40 \%(p<0.001)$ but FAT treatment significantly blocked this decrease in PIP synthesis in a dose-dependent manner $(p<0.001)$. To assist in the construction of extra cellular matrix (ECM), synthesized PIP must be secreted into the extracellular milieu. We determined the level of secreted PIP by the ELISA method, FAT treatment (500 and 1,000 $\mu \mathrm{g} / \mathrm{ml}$ ) increased the secretion of PIP by over 15\% under basal conditions (Fig. 4A). Although UVB irradiation caused a $47.2 \%$ reduction in PIP secretion, FAT treatment (500 and 1,000 $\mu \mathrm{g} / \mathrm{ml}$ ) significantly reversed this decrease (Fig. 4B). These results indicate that 


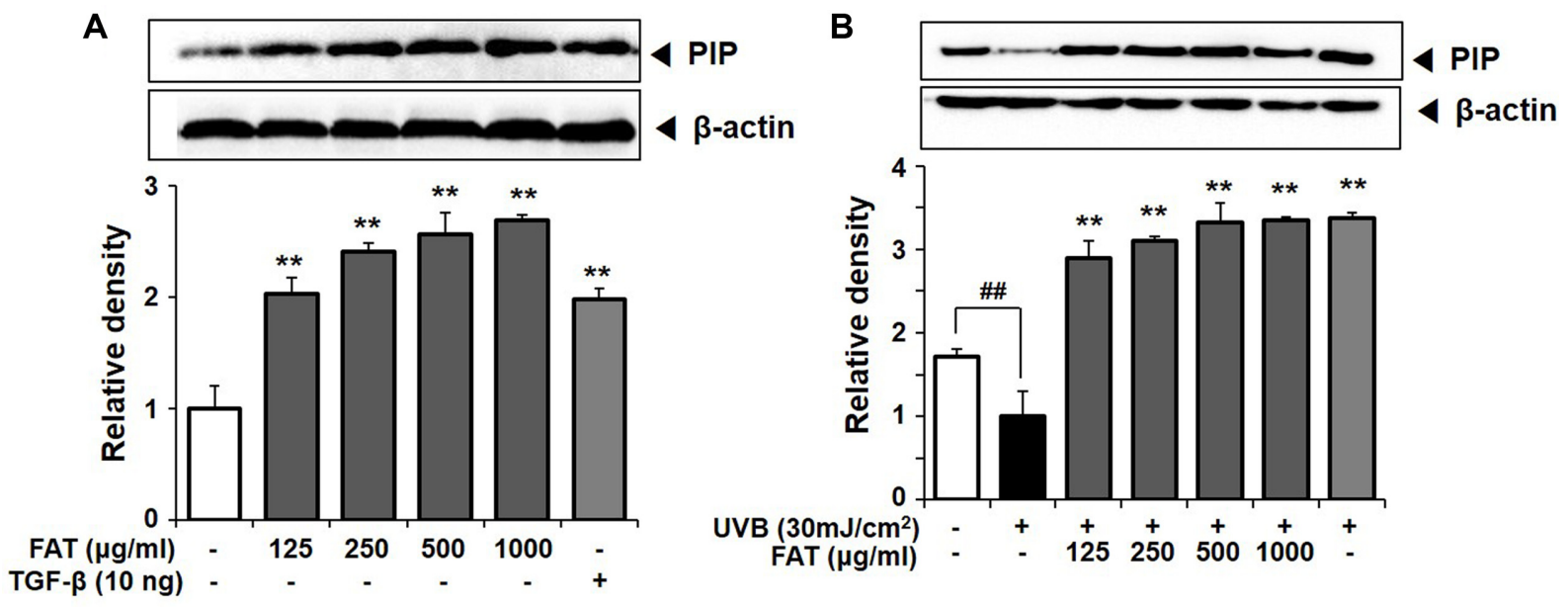

Fig. 3. Effect of FAT on the synthesis of procollagen Type I C-peptide (PIP).

Hs68 cells were treated with FAT $(0-1,000 \mu \mathrm{g} / \mathrm{ml})$ for $48 \mathrm{~h}$ and then cell content of procollagen Type I C-peptide (PIP) was determined by immunoblot analysis (A). After irradiation UVB irradiation $\left(30 \mathrm{~mJ} / \mathrm{cm}^{2}\right)$, cells were further cultured in the presence of FAT $(0-1,000 \mu \mathrm{g} / \mathrm{ml})$ for $48 \mathrm{~h}$. The cell PIP contents were determined by immunoblot analysis (B). TGF- $\beta$ was used as a positive control for PIP synthesis. Data are mean \pm $\operatorname{SEM}(n=6)$. \#\#p $<0.001$ compared to the untreated control. ${ }^{* *} p<0.001$ compared to the UVB-treated group.

FAT treatment could stimulate the synthesis and secretion of collagen in fibroblasts.

\section{Effect of FAT on the mRNA Expression Level of MMP-1}

The amount of extracellular matrix is regulated by the rates of synthesis and degradation of its components. MMP-1, encoded by the MMP1 gene in humans, is known to be an interstitial and fibroblast collagenase, which is involved in the breakdown of ECM in normal physiological processes and tissue remodeling. It has been suggested that wrinkle formation and dryness could be attenuated by down-regulating MMP-1 and upregulating expression of elastin, TGF- $\beta 1$, and procollagen type 1 in UVB-irradiated hairless mice [16]. As shown in Fig. 5, the mRNA level of MMP-1 was significantly suppressed by FAT treatment (500 and 1,000 $\mu \mathrm{g} / \mathrm{ml}$ ) in Hs68 cells. This suppressive potential of FAT was also found in the upregulation of MMP-1 caused by UVB irradiation (Fig. 5B).

\section{Effect of FAT on the mRNA Expression Level of Elastase} and Its Activity

Elastin is an important matrix protein and its reduction
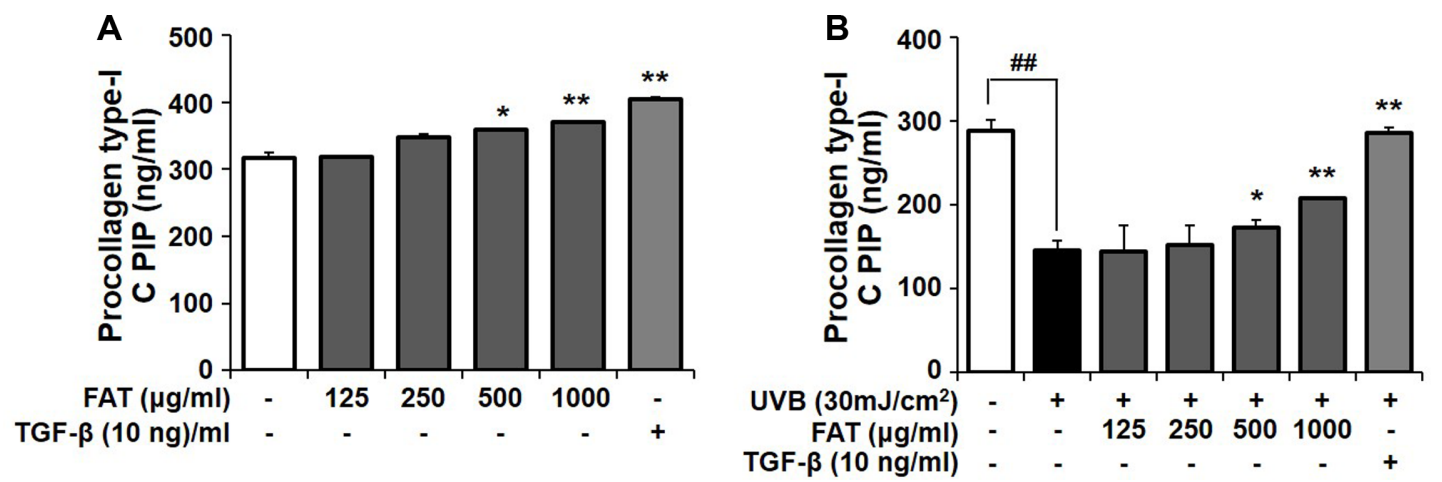

Fig. 4. Effect of FAT on the secretion of PIP.

Hs68 cells were treated with different concentrations of FAT in the absence (A) or presence of $30 \mathrm{~mJ} / \mathrm{cm}^{2} \mathrm{UVB}$ irradiation (B). After $24 \mathrm{~h}$, the amount of secreted procollagen Type I C-peptide (PIP) in the culture supernatant was determined using an EIA kit. TGF- $\beta$ (10 ng/ml) was used as a positive control for the suppression of PIP mRNA expression. \#\#p $<0.001$ compared to the untreated control. ${ }^{*}$ and ${ }^{* *} p<0.05$ and $p<0.001$ compared to the UVB treated control group, respectively. 

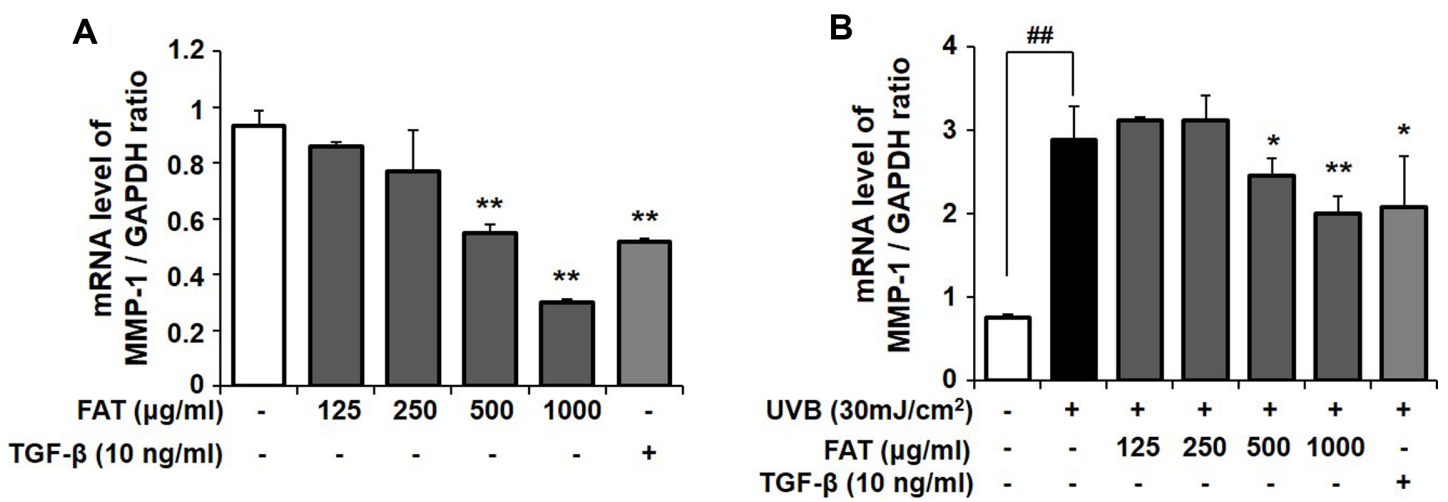

Fig. 5. Effect of FAT on the mRNA expression of MMP-1.

Hs68 cells were treated with different concentrations of FAT in the absence (A) or presence of $30 \mathrm{~mJ} / \mathrm{cm}^{2} \mathrm{UVB}$ irradiation (B). After $24 \mathrm{~h}$, the mRNA expression level of MMP-1 was determined by quantitative PCR. TGF- $\beta$ (10 ng/ml) was used as a positive control for the suppression of MMP-1 mRNA expression. \#\#p $<0.001$ compared to the untreated control. * and ${ }^{* *} p<0.05$ and $p<0.001$ compared to the UVB treated control group, respectively.

may also be associated with enhanced wrinkle formation. Elastase degrades elastin in the skin matrix. We determined the effect of FAT on the mRNA expression of elastase- 1 by quantitative PCR and its enzymatic activity by a colorimetric method. Here, phosphoramidon was used as a positive control for elastase inhibition [17]. Compared to MMP-1, FAT treatment $(125-1,000 \mu \mathrm{g} / \mathrm{ml})$ could significantly suppress the mRNA expression of elastase- 1 in a dosedependent manner in the absence of UVB exposure (Fig. 6A). In addition, the suppressive effect of FAT (500 and $1,000 \mu \mathrm{g} / \mathrm{ml}$ ) on the mRNA expression of elastase- 1 was shown in the UVB irradiated condition (Fig. 6B). In line with the suppression of elastase- 1 mRNA expression, a decrease in elastase activity was also shown in the presence of FAT (500 and 1,000 $\mu \mathrm{g} / \mathrm{ml}$ ) (Fig. 6C). Although UVB exposure caused a significant 1.5 -fold increase in elastase activity $(p<0.05)$, FAT treatment caused a significant reduction in the elastase activity (Fig. 6D), which may be associated with the increased expression level of elastase-1 (Fig. 6B). In conjunction with the results shown in Figs. 3 and 4 , it is speculated that FAT treatment may be involved in the maintenance of ECM through the stimulation of collagen production and inhibition of its degradation via the suppression of MMP-1 (Fig. 5) and elastase (Fig. 6).

\section{Effect of FAT on the Protein Expression of HO-1 and COX-2}

The protein expression level of HO-1 was determined in the presence of FAT with and without UVB exposure in HaCaT cells. FAT treatment at concentrations above $125 \mu \mathrm{g} / \mathrm{ml}$ significantly stimulated protein expression of
HO-1. Furthermore, the UVB-mediated increase of HO-1 expression was strengthened in the presence of FAT (500 and $1,000 \mu \mathrm{g} / \mathrm{ml}, p<0.05)$. These results suggest that FAT treatment enhances HO-1 expression and may thereby provide additional protective potential against UVBmediated skin damage. In addition, to further resolve the involvement of $\mathrm{HO}-1$ in the process of wound healing followed by UVB irradiation, wound filling rate was measured in the presence or absence of $\mathrm{ZnPP}(20 \mu \mathrm{M})$, an HO-1 inhibitor, in HaCaT cells. When HO-1 was inhibited by $\mathrm{ZnPP}$, the rate of wound filling was significantly decreased compared to that in the UVB irradiated group (Fig. 7C). This result suggests that upregulation of HO-1 plays an important role in the wound filling process following UVB irradiation as its suppression impairs the rate of the wound healing process.

UVB irradiation in mouse skin induces extensive COX-2 gene activation and COX-2 protein accumulation [18]. Thus, in the present study, we investigated the effect of FAT treatment on the UVB-mediated upregulation of COX2 in $\mathrm{HaCaT}$ cells since suppression of COX-2 activation could be beneficial in the amelioration of wrinkle formation. UVB exposure caused significant induction of COX-2 protein expression (Fig. 8), but this increase in COX2 expression was suppressed in the presence of FAT $(62.5$ and $125 \mu \mathrm{g} / \mathrm{ml}$ ). It has been suggested that, in murine brain endothelial cells, the inhibitory effect of HO-1 on COX-2 expression was mediated through the inhibition of NF- $\mathrm{KB}$ and could be reversed by an $\mathrm{HO}$ inhibitor $\mathrm{ZnPP}$ [19]. To determine the possible involvement of HO-1 in the UVBmediated upregulation of COX-2, immunoblot analysis of 
A

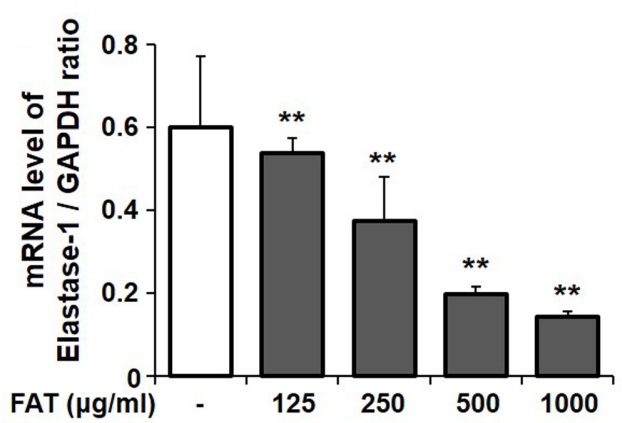

C

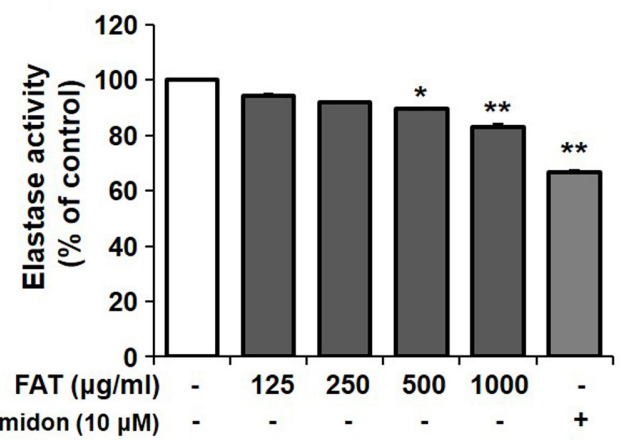

B

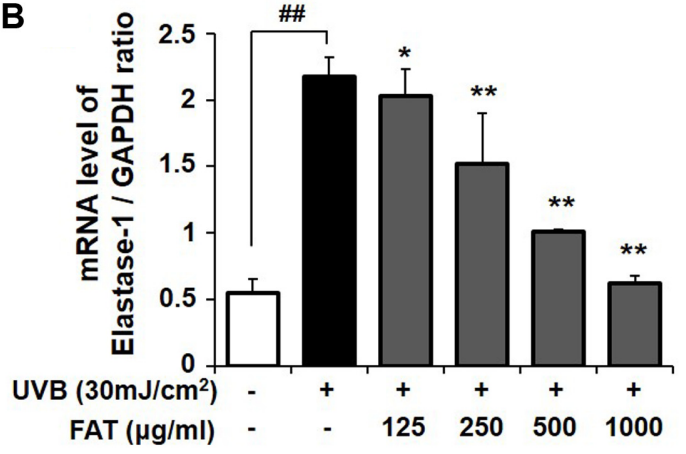

D

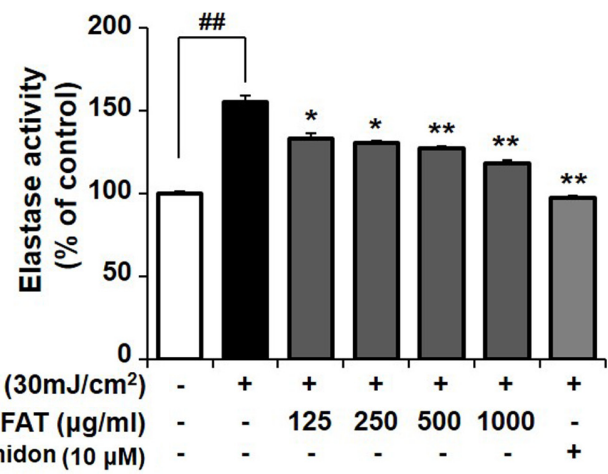

Fig. 6. Effect of FAT on the regulation of elastase-1.

Hs68 cells were treated with different concentrations of FAT in the presence or absence of $30 \mathrm{~mJ} / \mathrm{cm} 2 \mathrm{UVB}$ irradiation. After $24 \mathrm{~h}$, the mRNA expression level of elastase-1 was determined by quantitative PCR (A, B) and its enzymatic activity was measured using ELISA assay from the whole cell lysate following FAT treatment at $48 \mathrm{~h}(\mathbf{C}, \mathbf{D})$. Phosphoramidon $(10 \mu \mathrm{M})$ was used as a positive control for the suppression of elastase activity. \#\#; $p<0.001$ compared to the untreated control. ${ }^{*}$ and ${ }^{* *} ; p<0.05$ and $p<0.001$ compared to the UVB treated control group, respectively.

COX-2 was conducted in the presence or absence of ZnPP. The protein expression of COX-2 was significantly blocked by $\mathrm{ZnPP}$ treatment. In addition, the suppression of COX-2 expression caused by FAT treatment was also dampened in the presence of $\mathrm{ZnPP}$. These results suggest that induction of COX-2 was, at least in part, influenced by the action of HO-1, because COX-2 expression was not completely blunted by $\mathrm{ZnPP}$ treatment. Although FAT treatment at the dose of $62.5 \mu \mathrm{g} / \mathrm{ml}$ did not affect the protein expression level of HO-1 (Fig. 7A), the UVB-mediated induction of COX-2 was significantly suppressed at this dose (Fig. 8). Therefore, we speculate that FAT may suppress the induction of COX-2 by HO-1-dependent and -independent mechanisms.

\section{Discussion}

In the present study, we demonstrated that FAT treatment could stimulate wound healing under the basal condition. FAT favored the maintenance and/or improvement of
ECM caused by UVB irradiation through: 1) upregulation and secretion of procollagen Type-1 synthesis; 2) suppression of MMP-1 and elastase expression. FAT was able to play a role in the attenuation of inflammatory responses caused by UVB irradiation via upregulation of photo-protective HO-1 and suppression of proinflammatory COX-2 expression. These effects of FAT to combat skin photoaging caused by UVB exposure may be beneficial on the reduction of unfavorable wrinkle formation.

Chronological aging and photoaging causes the decline in skin structure and function, resulting in the formation of wrinkles as reviewed elsewhere [14, 15]. As an indicator of youth and beauty, clear unwrinkled skin is a very important part of a satisfactory appearance and quality of life, especially for Asian women [1]. In addition to intrinsic or chronological aging, repeated exposure of the skin to sunlight activates numerous signaling pathways that lead to decreased collagen production, and increased synthesis and activity of matrix metalloproteases (MMPs) that are responsible for connective tissue degradation, accumulation 

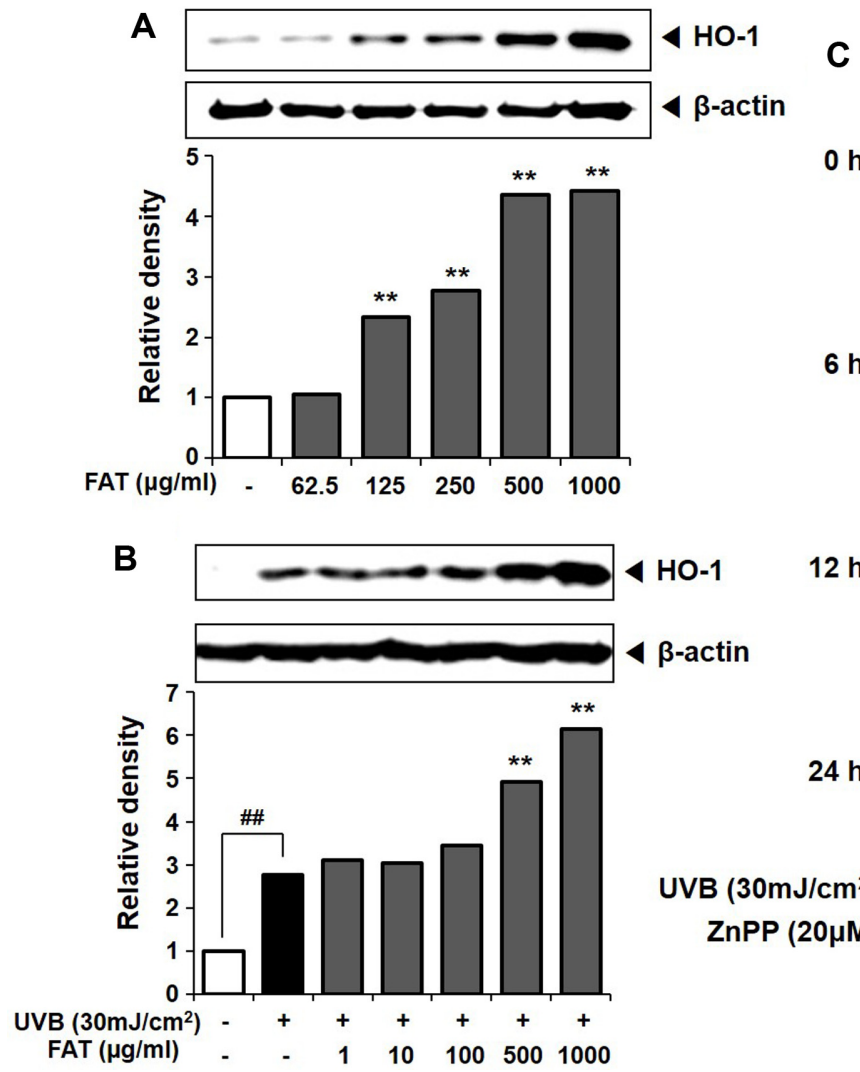

C

$\mathrm{Oh}$

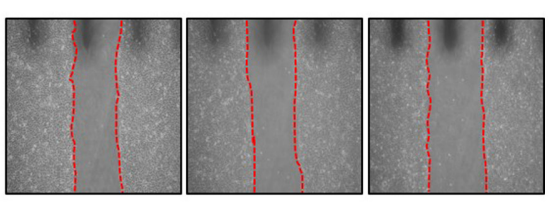

$6 \mathrm{~h}$

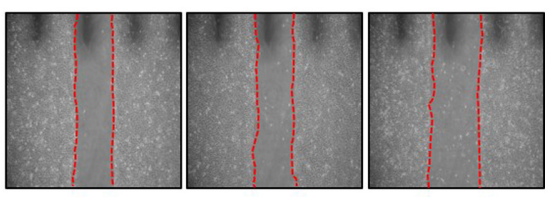

$2 \mathrm{~h}$

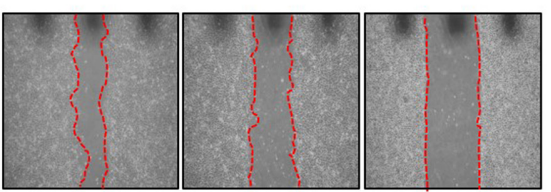

$24 \mathrm{~h}$

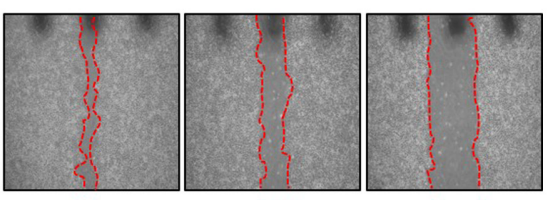

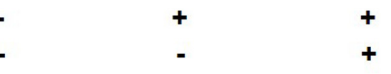

Fig. 7. Effect of FAT on the expression of HO-1 and its involvement on the wound healing process.

$\mathrm{HaCaT}$ cells were treated with different concentrations of FAT in the absence (A) or presence of $30 \mathrm{~mJ} / \mathrm{cm}^{2}$ UVB irradiation (B). After $24 \mathrm{~h}$, whole cell lysates were subjected to immunoblot analysis to determine the HO-1 expression level. Cells were exposed to the same dose of UVB and then a scratch was made on the confluent HaCaT cell layer (C). After $24 \mathrm{~h}$, the rate of cell migration was visualized under a microscope and then images were randomly captured. \#\#p $<0.001$ compared to the untreated control. ${ }^{*}$ and ${ }^{* *} p<0.05$ and $p<0.001$ compared to the UVB treated control group, respectively.

of senescent cells, and other effects [14]. Coarse and fine wrinkle formation in the skin is caused by deleterious alterations in the collagenous extracellular matrix and seems to be a sign of aging. Furthermore, the suppression of photoaging plays an important role in the prevention of UVB-mediated skin cancer. In the skin, wrinkle formation, hyperpigmentation, and sallowness following UVB insult are caused by a complex multifactorial etiology [14, 15]. Among these factors, inhibition of collagen synthesis, the breakdown of collagen and ECM, apoptotic cell death and the accumulation of senescent cells are major contributors in skin aging. Wound healing is a dynamic process consisting of four continuous, overlapping, and precisely programmed phases: hemostasis, inflammation, proliferation, and remodeling orchestrated by keratinocytes, fibroblasts, endothelial cells, and macrophages [20]. Migration of the healing cells to the wound or inflamed site is crucial to achieve accelerated healing with minimal loss or changes in the tissue architecture [21, 22]. FAT was able to enhance cell migration (Fig. 2) without cell proliferation in vitro (Fig. 1). We speculate that rapid wound repair is essential to protect against environmental stresses and mitigate unfavorable expansion of the inflammatory responses.

HO-1 is a downstream antioxidant enzyme that is regulated by the redox sensitive transcription factor Nrf2 and plays a critical protective role in limiting oxidative damage in a UVB-induced model [23]. The increase in HO1 expression following UVB exposure ameliorates skin inflammation and extracellular matrix damages [23]. FAT treatment was able to upregulate the expression of photoprotective HO-1 in the presence of absence of UVB irradiation (Fig. 7).

The inflammatory response in the skin will accelerate wrinkle formation [24]. COX-2 is another important 

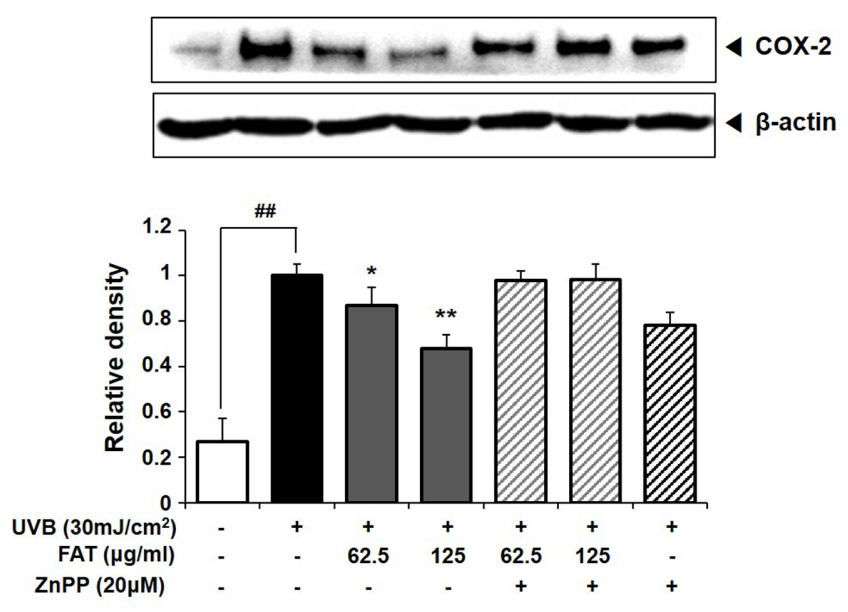

Fig. 8. Effect of FAT on the UVB irradiation mediated upregulation of COX-2.

After UVB irradiation $\left(30 \mathrm{~mJ} / \mathrm{cm}^{2}\right)$, HaCaT cells were treated with different concentrations of FAT for $48 \mathrm{~h}$. Then whole cell lysates were subjected to immunoblot analysis ( $n=6$ per group). \#\# $p<0.001$ compared to the untreated control. ${ }^{*}$ and ${ }^{* *} p<0.05$ and $p<0.001$ compared to the UVB treated control group, respectively.

modulator in the inflammatory response and increased COX-2 expression occurs during the aging process due to NF-kappa B activation [25]. Alternatively, it is speculated that FAT treatment may be involved in the suppression of UVB-mediated COX-2 induction through HO-1 activation, since the inhibitory effect of FAT on COX-2 expression was partly blunted by ZnPP (Fig. 8). In the maintenance of the ECM in skin, FAT treatment could be beneficial, because collagen synthesis and secretion were increased in the presence of FAT and the expression and activities of both MMP-1 (Fig. 5) and elastase-1 (Fig. 6) were also significantly suppressed. The magnitude of HO-l induction after oxidative stress and the wide distribution of this enzyme in systemic tissues, coupled with the intriguing biological activities of the catalytic byproducts, carbon monoxide, iron, and bilirubin [26] make this an intriguing avenue for further investigation. As shown in Fig. 7, FAT could upregulate the expression of $\mathrm{HO}-1$ both at basal condition and following UVB-irradiation but the underlying mechanism involved in the induction of HO-1 induction by FAT treatment remains unclear. This issue should be investigated in future studies. It should be noted that, in addition to topical antioxidant treatment, oral antioxidant therapies have also been shown to be effective in preventing sun damage to skin [3]. Considering animal welfare and the largely accepted ban on animal experimentation in cosmeceutical sciences, investigation of the effect of oral supplementation of FAT to protect against photoaging may be valuable but should be carefully considered in designing future experiments.

In conclusion, FAT did not show any significant effect on cell death or proliferation in either HaCaT or Hs68 cells. FAT was able to accelerate wound filling under basal conditions in keratinocytes forming the epidermal layer. FAT treatment could not only inhibit mRNA expression of MMP-1 and elastase but also increase collagen content as shown by the production and secretion of procollagen type I with or without UVB exposure. FAT treatment could be beneficial in the suppression of UVB-mediated wrinkle formation and/or the photoaging of skin through increased PIP levels and decreased MMP-1 and elastase activities. Additionally, FAT showed beneficial regulation of the antioxidative enzyme $\mathrm{HO}-1$, and the anti-inflammatory enzyme COX-2 for skin health under UV stress. However, the underlying molecular mechanism of FAT treatment will need to be further elucidated by future experiments. These findings suggest that FAT has the skin anti-photoaging potential to be an effective anti-aging and anti-wrinkle cosmetic agent.

\section{Acknowledgments}

This research was supported by the Ministry of Trade, Industry \& Energy (MOTIE), Korea Institute for Advancement of Technology (KIAT) through the Encouragement Program for The Industries of Economic Cooperation Region.

\section{Conflict of Interest}

The authors have no financial conflicts of interest to declare.

\section{References}

1. Smit N, Vicanova J, Pavel S. 2009. The hunt for natural skin whitening agents. Int. J. Mol. Sci. 10: 5326-5349.

2. Yaar M, Gilchrest BA. 1998. Aging versus photoaging: postulated mechanisms and effectors. J. Invest. Dermatol. Symposium Proceedings 3: 47-51.

3. Allemann IB, Baumann L. 2009. Botanicals in skin care products. Int. J. Dermatol. 48: 923-934.

4. Ka MH, Choi EH, Chun HS, Lee KG. 2005. Antioxidative activity of volatile extracts isolated from Angelica tenuissimae roots, peppermint leaves, pine needles, and sweet flag leaves. J. Agric. Food Chem. 53: 4124-4129.

5. Han BH, Sung CK, Takeatsu K, But PPH, Guo J-X. 1998. 
International Collation of Traditional and Folk Medicine pp. Ed. World Scientific Publishing Co. Pte. Ltd., Signapore.

6. Kim CM, Sin MK, Ahn DK, Lee KS, Dictionary of Chinese Materia Medica [in Korean], Jungdam Publishing S, 1997, 255 pp. 1997. Dictionary of Chinese Materia Medica [in Korean], pp. 255. Ed. Jungdam Publishing, Seoul.

7. Weeratunga P, Uddin MB, Kim MS, Lee BH, Kim TH, Yoon JE, et al. 2016. Interferon-mediated antiviral activities of Angelica tenuissima Nakai and its active components. J. Microbiol. (Seoul, Korea) 54: 57-70.

8. Ahn SJ, Baek JM, Cheon YH, Park SH, Lee MS, Oh J, et al. 2015. The inhibitory effect of Angelica Tenuissima water extract on receptor activator of nuclear factor-kappa-B ligand-induced osteoclast differentiation and bone resorbing activity of mature osteoclasts. Am. J. Chin. Med. 43: 715-729.

9. Lee $\mathrm{SH}, \mathrm{Choi} \mathrm{H}, \mathrm{Kim} \mathrm{H}$, Lee H, Sung $\mathrm{YH}, \mathrm{Kim} \mathrm{SE}$, et al. 2010. Inhibitory effect of Angelicae Tenuissimae Radix on expressions of cyclooxygenase- 2 and inducible nitric oxide synthase in mouse BV2 microglial cells. Neurol. Res. 32 (Suppl 1): 58-63.

10. Shin YK, Son HU, Kim JM, Heo JC, Lee SH, Kim JG. 2015. Cinnamomum cassia bark produced by solid-state fermentation with Phellinus baumii has the potential to alleviate atopic dermatitis-related symptoms. Int. J. Mol. Med. 35: 187-194.

11. Kim OK, Chang JY, Nam DE, Park YK, Jun W, Lee J. 2015. Effect of Canavalia gladiata extract fermented with Aspergillus oryzae on the development of atopic dermatitis in NC/Nga mice. Int. Arch. Allergy Immunol. 168: 79-89.

12. Park Y, Kim D, Yang I, Choi B, Lee JW, Namkoong S, et al. 2018. Decursin and Z-ligustilide in Angelica tenuissima root extract fermented by Aspergillus oryzae display anti-pigment activity in melanoma cells. J. Mirobiol. Biotechnol. 28: 1061-1067.

13. Liu H, Yue J, Lei Q, Gou X, Chen SY, He YY, et al. 2015. Ultraviolet B inhibits skin wound healing by affecting focal adhesion dynamics. Photochem. Photobiol. 91: 909-916.

14. Cavinato M, Waltenberger B, Baraldo G, Grade CVC, Stuppner H, Jansen-Durr P. 2017. Plant extracts and natural compounds used against UVB-induced photoaging. Biogerontology 18: 499-516.

15. Rittie L, Fisher GJ. 2015. Natural and sun-induced aging of human skin. Cold Spring Harbor Perspectives in Medicine. 5: a015370.
16. Park B, Hwang E, Seo SA, Cho JG, Yang JE, Yi TH. 2018. Eucalyptus globulus extract protects against UVB-induced photoaging by enhancing collagen synthesis via regulation of TGF-beta/Smad signals and attenuation of AP-1. Arch. Biochem. Biophys. 637: 31-39.

17. Morihara K, Tsuzuki H. 1978. Phosphoramidon as an inhibitor of elastase from Pseudomonas aeruginosa. Jap. J. Exp. Med. 48: 81-84.

18. Athar M, An KP, Morel KD, Kim AL, Aszterbaum M, Longley $\mathrm{J}$, et al. 2001. Ultraviolet B(UVB)-induced cox-2 expression in murine skin: an immunohistochemical study. Biochem. Biophys. Res. Commun. 280: 1042-1047.

19. Shih R-H, Yang C-M. 2010. Induction of heme oxygenase-1 attenuates lipopolysaccharide-induced cyclooxygenase-2 expression in mouse brain endothelial cells. J. Neuroinflammation 7: 86.

20. Guo S, DiPietro LA. 2010. Factors affecting wound healing. J. Dental Res. 89: 219-229.

21. Anitua E, Troya M, Orive G. 2012. Plasma rich in growth factors promote gingival tissue regeneration by stimulating fibroblast proliferation and migration and by blocking transforming growth factor-beta1-induced myodifferentiation. J. Periodontol. 83: 1028-1037.

22. Semlali A, Chakir J, Goulet JP, Chmielewski W, Rouabhia M. 2011. Whole cigarette smoke promotes human gingival epithelial cell apoptosis and inhibits cell repair processes. J. Periodontal Res. 46: 533-541.

23. Black AT, Gordon MK, Heck DE, Gallo MA, Laskin DL, Laskin JD. 2011. UVB light regulates expression of antioxidants and inflammatory mediators in human corneal epithelial cells. Biochem. Pharmacol. 81: 873-880.

24. Rundhaug JE, Fischer SM. 2008. Cyclo-oxygenase-2 plays a critical role in UV-induced skin carcinogenesis. Photochem. Photobiol. 84: 322-329.

25. Kim HJ, Kim KW, Yu BP, Chung HY. 2000. The effect of age on cyclooxygenase-2 gene expression: NF-kappaB activation and IkappaBalpha degradation. Free Radic. Biol. Med. 28: 683-692.

26. Choi AM, Alam J. 1996. Heme oxygenase-1: function, regulation, and implication of a novel stress-inducible protein in oxidant-induced lung injury. Am. J. Resp. Cell Mol. Biol. 15: 9-19. 